\title{
Study of Serum Spexin Level in Obese and Non-Obese type 2 Diabetic Patient
}

\author{
Yasmin S. Mashaal', Attaa M. Bakr², Azza A. El-Baiomy ${ }^{3}$, Naglaa E. Abbas ${ }^{2 *}$ \\ ${ }^{1}$ Department of Internal Medicine, Zarka Central Hospital, Egypt, ${ }^{2}$ Department of Internal Medicine, \\ Endocrinology Unit, Faculty of Medicine, Mansoura University, and '3epartment of Clinical Pathology, Faculty \\ of Medicine, Mansoura University, Mansoura, Egypt
}

\begin{abstract}
Background: Spexin is a peptide, which is discovered as an important regulatory adipokine in obesity, insulin resistance (IR), and diabetes. Aim: To evaluate serum Spexin levels in type-2 diabetic obese patients in comparison to its levels in non-obese diabetic (NOD) and to assess its relationship to IR and glycemic control. Patients and methods: A total of 20 NOD (group 1), 22obese nondiabetic (OND) (group 2), and 240bese diabetic patients (OD) (group 3), with an average age of $43.8 \pm 8.9,49 \pm 8.8,45.1 \pm 11.6$ years respectively, and 20 age and sex-matched healthy participants (control group) were included. Height and weight were measured using standard techniques. Glucose levels, triglycerides (TG), total cholesterol (TC), high-density lipoprotein cholesterol (HDL-C), low-density lipoprotein cholesterol (LDL-C), fasting insulin ( $\mathrm{FI})$, calculation of Homeostasis model assessment insulin resistance (HOMA-IR), and Spexin levels were measured in each patient. Results: The median serum Spexin levels were significantly lower in the OD than in the other groups and lower in the NOD and OND than in the non-obese non-diabetic (NOND)( $p$ $<0.001)$. Spexin level at a cutoff value $\leq 0.70$ can significantly discriminate OD from NOND. Spexin levels were negatively correlated with age, body mass index (BMI), LDL-C, TG, FI, and HOMA-IR. Conclusion: Spexin plays an important role in glucose homeostasis and lipid metabolism. The presence of diabetes is associated with lower Spexin levels. Further investigations and additional studies in larger populations are required to understand the exact function of this peptide and to validate the observations in the current study.
\end{abstract}

Keywords: Obesity, diabetes, adipokine, insulin resistance

\section{Introduction}

Diabetes Mellitus (DM) is a metabolic chronic disorder, which is characterized by chronic elevation of the blood glucose level. In2015, nearly 415 million adult subjects with ages ranging from 20 to 79 years suffered from $D M^{(1)}$. It is a global public health burden as this number is expected to rise to another 200 million by 2040 . Approximately 1 in 11 adults all over the world suffer from DM, 90\% of them are Type II DM $\left(T_{2} D M\right)^{(2)}$. The major factors contributing to the increasing rates of T2DM are the increase in a sedentary lifestyle, obesity, and aging of the population(3). High levels of adiposity, evaluated by increased $\mathrm{BMI}$, are the single main risk factor for the 
development of $\mathrm{T}_{2} \mathrm{DM}^{(4)}$ and are related to several metabolic abnormal defects which lead to $\mathrm{IR}^{(5)}$. Obesity management by using an operation for weight loss has been demonstrated to be successful to prevent and treat cases suffering from $\mathrm{T}_{2} \mathrm{DM}^{(6)}$. Spexin is a neuropeptide generated in the white fatty tissue, brain, heart, thyroid, lung, ovary, liver, adrenal, testis, pancreas, muscle, and stomach ${ }^{(7)}$. It was recognized as a significant regulator of obesity and its associated metabolic disorders including $\mathrm{IR}$ and $\mathrm{DM}^{(6)}$. Preliminary studies in mice with diet-induced obesity, T2DM, and hepatic steatosis suggest that the administration of Spexin may be an effective treatment for these three conditions ${ }^{(8)}$. Spexin role is not well recognized; and the strict mechanisms throughout which Spexin applies its effects are unclear even now, due to insufficient information available on the receptors of Spexin (9). Walewski et al. found a considerably lower concentration of Spexin in obese than in lean adults and suggested a possible satiety-inducing function for it in humans ${ }^{(10)}$. Decreased levels of Spexin have been detected in T2DM patients compared to the non-diabetic people, which recommends that Spexin may affect the metabolism of lipid and glucose $^{(11)}$. Insulin and Spexin localization in $\beta$ cells were established in pigs and humans, but not in mice ${ }^{(12)}$. This denotes that Spexin possibly could affect the function of the pancreas. The present study aimed to: evaluate serum Spexin levels in type-2 diabetic obese patients in comparison to its levels in NOD and to assess its relationship to IR and glycemic control

\section{Subjects and Methods}

This case-control study included 44 patients with T2DM (24 OD, 20 NOD) and 22 OND, with a mean age of 45.1 \pm 11.6 ,
$43.8 \pm 8.9$, and $49 \pm 8.8$ years respectively, selected from the Outpatient Clinics of Mansoura University Hospital, Faculty of Medicine, Egypt, from March 2018 to February 2019. Moreover,20 healthy controls matched for sex and age were also selected from the same locality. Informed consent was obtained from all participants, and approval was given by the ethics committee of our institution. DM was diagnosed according to the American Diabetes Association (ADA) criteria ${ }^{(13)}$. We excluded patients who had Type $1 \mathrm{DM}$, lean patients, patients with intrinsic renal or hepatic diseases, patients with organ failure, and patients who had an endocrinal cause of obesity or diabetes. Full history and clinical examination were taken from all participants. The patient's height and weight were measured using standard techniques. BMI was calculated as weight in kilograms divided by height in meters squared $\left(\mathrm{kg} / \mathrm{m}^{2}\right)$. Blood pressure (BP) was taken in the sitting position using a random-zero sphygmomanometer. Venous blood samples after overnight fasting were collected. Creatinine level in the blood serum was determined. Serum TG levels were estimated according to the Allain et al. method(14). TC was estimated according to the Fossati and Prencipe ${ }^{(15)}$ method. Serum HDL-C was estimated according to the Williams et al. method $^{(16)}$. LDL-C levels in blood serum were calculated according to the equation, which was described by Trinder(17): LDL$\mathrm{C}=\mathrm{TC}-\mathrm{HDLC}-\mathrm{TG} / 5$. Estimation of blood glucose was performed according to the Trivedi et al. method ${ }^{(18)}$. Serum insulin was assayed by ELISA supplied by Eagle Biosciences, Inc. Catalog Number: INS31-K0120A (Northwest Blvd., Suite 112, Nashua, NH 03063). Calculation of HOMA-IR. *HOMA= Fasting glucose (mgldl) X Fl (ml u/ml)/405 (19). Spexin was assayed by ELISA kits supplied by Mybiosource (USA). This kit 
utilizes ELISA depending on the Avidin-Biotin complex technology. Addition of Spexin (C12orf39) to the wells that are coated with monoclonal antibody of Spexin (C12orf39) and after that undergo incubation for a certain period. Then, putting anti C12orf39 antibodies that are labeled by biotin for uniting with streptavidin-HRP leads to the formation of the immunocomplex. Washing to get rid of the excess unbound enzymes after the termination of the incubation period. In addition to substrate $A$ and $B$, then the solution will become blue and turn into yellow color with the acid effect.

\section{Statistical analysis}

Data were fed to the computer and ana- lyzed using IBM SPSS software package version 22.0. Qualitative data were described using numbers and percentages. Quantitative data were described using the mean. The standard deviation for parametric data after testing normality using Kolmogrov-Smirnov test, and median (minmax) for non-parametric data. The significance of the obtained results was judged at the (0.05) level.

\section{Results}

Table 1 shows an insignificant difference between groups regarding age $(P=0.3656)$ Female sex was higher in OD $(n=23)$ than in the NOND $(n=12)$ and the NOD $(n=13)$ $(p=0.011)$. TC was significantly higher in the OD than in the control group,

Table 1: Clinical and biochemical characteristics of the study groups

\begin{tabular}{|l|c|c|c|c|c|}
\hline Variable & NOND $(\mathrm{n}=20)$ & NOD $(\mathrm{n}=20)$ & OND $(\mathrm{n}=22)$ & OD $(\mathrm{n}=24)$ & P value \\
\hline Sex $(\mathrm{n} \%)$ & & & & & \\
Males & $8(40 \%)$ & $7(35 \%)$ & $3(13.6 \%)$ & $1(4.2 \%)$ & 0.011 \\
Females & $12(60 \%)$ & $13(65 \%)$ & $19(86.4 \%)$ & $23(95.8 \%)$ & \\
\hline Age $($ years) & $45.63 \pm 8.6$ & $43.8 \pm 8.9$ & $4.9 \pm 8.8$ & $45.1 \pm 11.6$ & 0.3656 \\
\hline SBP $(\mathrm{mmHg})^{*}$ & $118.5 \pm 13.9$ & $126.5 \pm 15.3$ & $125.9 \pm 12.6$ & $134.6 \pm 18.9$ & 0.011 \\
\hline DBP $(\mathrm{mmHg})^{*}$ & $73 \pm 8.6$ & $76 \pm 13.1$ & $77.7 \pm 10.2$ & $77.5 \pm 11.1$ & 0.479 \\
\hline TC* & $232.8 \pm 63.7$ & $254.1 \pm 79.0$ & $267.8 \pm 95.7$ & $311.6 \pm 124.2$ & 0.049 \\
\hline LDL-C $^{*}$ & $130 \pm 58.2$ & $135 \pm 79.1$ & $167 \pm 94.1$ & $188.7 \pm 113.7$ & 0.109 \\
\hline HDL-C & $65.5 \pm 15.9$ & $64.0 \pm 17.5$ & $60.5 \pm 16.1$ & $62.7 \pm 19.3$ & 0.818 \\
\hline TC $^{*}$ & $187.9 \pm 98.6$ & $277.7 \pm 112.2$ & $202.7 \pm 90.5$ & $303.3 \pm 107.4$ & $<0.001$ \\
\hline Fasting insulin@ & $2.4(1.4-3.9)$ & $4.3(3.5-5.1)$ & $4.9(3.9-6.0)$ & $7.15(5.90-11.75)$ & $<0.001$ \\
\hline HOMA-IR@ & $0.54(0.28-0.82)$ & $2.49(1.37-3.16)$ & $1.13(0.95-1.63)$ & $3.43(1.69-4.71)$ & $<0.001$ \\
\hline
\end{tabular}

${ }^{*}$ Data are presented as (Mean \pm SD), @ Data are presented as median (IQR), P-value: One-Way ANOVA. NOND: Non-obese nondiabetic, NOD; non obese diabetic, OND; obese non-diabetic, OD; obese diabetic. SBP: systolic blood pressure, DBP: diastolic blood pressure, HOMA-IR; Homeostasis model assessment insulin resistance, TC; Total cholesterol, LDL-C: low-density lipoprotein cholesterol, TG: triglyceride, HDL-C: high-density lipoprotein cholesterol.

difference between the four groups ( $p$ $=0.049)$. TG was significantly higher in the OD than in the OND $(p<0.001)$ and higher in the NOD than in the control group $(p<0.001)$. The other tested parameters such as FI was significantly higher in the OD than in all three other groups. HOMA-IR was higher in the OD than in the OND and
NOND $(p<0.001)$. It was also higher in the OD than in the NOD, but this difference was not statistically significant. Tables 2 and 3 show that the serum levels of Spexin were significantly lower in OD than in all other three groups and were lower in the NOD and OND than in the NOND $(p<0.001)$. Spexin levels at cutoff value $\leq 0.70$ can 


\begin{tabular}{|c|c|c|c|c|c|c|}
\hline Statistic & $\begin{array}{l}\text { NOND } \\
(n=20)\end{array}$ & $\begin{array}{c}\text { NOD } \\
(n=20)\end{array}$ & $\begin{array}{c}\text { OND } \\
(\mathrm{n}=22)\end{array}$ & $\begin{array}{c}O D \\
(n=24)\end{array}$ & $\begin{array}{l}\text { KW } \\
\text { value }\end{array}$ & P-value \\
\hline $\begin{array}{l}\text { Median } \\
\text { (IQR) }\end{array}$ & $\begin{array}{c}1.85 \\
(0.83-2.27)\end{array}$ & $\begin{array}{c}0.7 \\
(0.7-0.7)\end{array}$ & $\begin{array}{c}0.7 \\
(0.6-0.7)\end{array}$ & $\begin{array}{c}0.6 \\
(0.52-0.6)\end{array}$ & \multirow[b]{3}{*}{72.579} & \multirow[b]{3}{*}{$<0.001$} \\
\hline Range & $0.8-3.8$ & $0.7-0.8$ & $0.6-0.7$ & $0.17-0.6$ & & \\
\hline $\begin{array}{l}\text { Pairwise } \\
\text { comparisons }\end{array}$ & A & B & B & $C$ & & \\
\hline
\end{tabular}

$P$ value: Kruskal -Wallis H test. IQR; inter quartile range. Similar letters = Insignificant difference, Different letters = Significant difference. NOND; Non-obese non diabetic, NOD; non obese diabetic, OND; obese non diabetic, OD; obese diabetic.

Table 3: Spexin cutoff values in different groups

\begin{tabular}{|l|c|c|c|c|c|c|c|}
\hline Discrimination of & $\begin{array}{c}\text { Cutoff } \\
\text { value }\end{array}$ & P-value & AUC $(95 \% \mathrm{Cl})$ & SN & SP & PPV & NPV \\
\hline OD from NOND & $\leq 0.70$ & $<0.001$ & 1.0 & $100 \%$ & $100 \%$ & $100 \%$ & $100 \%$ \\
\hline OND from NOND & $\leq 0.75$ & $<0.001$ & 1.0 & $100 \%$ & $100 \%$ & $100 \%$ & $100 \%$ \\
\hline NOD from NOND & $\leq 0.75$ & $<0.001$ & $0.975(0.938-1.000)$ & $80 \%$ & $100 \%$ & $100 \%$ & $83.3 \%$ \\
\hline MS from Non-MS & $\leq 0.75$ & $<0.001$ & $0.783(0.677-0.889)$ & $94 \%$ & $60 \%$ & $77.4 \%$ & $87.5 \%$ \\
\hline
\end{tabular}

$A U C=$ Area under the Receiver operating characteristic curve, $P P V=P o s i t i v e$ predictive value. NPV=Negative predictive value, $S N=$ sensitivity, $S P=$ =specificity. NOND; non-obese non-diabetic, NOD; non-obese diabetic, OND; obese non-diabetic, OD; obese diabetic, MS; Metabolic Syndrome.

significantly discriminate OD from NOND. Spexin at a cutoff value of $\leq 0.75$ can significantly discriminate OND as well as NOD from NOND and discriminate metabolic syndrome (MS) from Non-MS ( $p<0.001)$. Tables 4 shows the associations between Spexin and other parameters. Spexin levels were negatively correlated with age, BMI, FI, LDL-C, TC, TG, and HOMA-IR. Tables 5 shows a significantly higher $\mathrm{BMI}$, WC, HC, WHR, FI, and HOMA-IR in the MS than in the NO-MS $(p<0.001)$.

\section{Discussion}

We have evaluated the serum Spexin levels in T2DM obese patients and assessed its relationship to IR and glycemic control, as the Spexin role is not well recognized, and its mechanism of action is still unclear. We found a non-significant difference between the four groups in age, as the age was matched.TC and TG levels were significantly higher in the OD than in the control group. Also, TG levels were significantly higher in the OD than in the OND. Moreover, TG levels were significantly higher in NOD than in the control group. The effects of obesity on lipid metabolism include elevated LDL-C, VLDL-C, TG, and low levels of protective HDL-C ${ }^{(20)}$. These results coincide with a previous study that reported elevated TG, VLDL, Apo B, and nonHDL-C levels in obese patients ${ }^{(21)}$. SBP was significantly higher in the OD than in the control group. There is a nearly linear relationship between $\mathrm{BMI}$ and $\mathrm{BP}$, and weight loss reduces $\mathrm{BP}$ in most hypertensive individuals $^{(22)}$. This result was matched with the results of Blüher ${ }^{(23)}$, who stated that obesity considerably augments the possibility of the development of diseases like T2DM, hypertension, fatty liver disease, stroke, myocardial infarction, osteoarthritis, and dementia. 


\begin{tabular}{|l|c|c|}
\hline \multicolumn{3}{|c|}{ Table 4: Correlation of Spexin to other study parameters } \\
\hline Parameter & Correlation coefficient & P-value \\
\hline Age & -0.413 & $<0.001$ \\
\hline BMI & -0.824 & $<0.001$ \\
\hline Fasting insulin & -0.600 & $<0.001$ \\
\hline HOMA-IR & -0.520 & $<0.001$ \\
\hline TC & -0.264 & 0.014 \\
\hline LDL-C & -0.216 & 0.046 \\
\hline HDL-C & -0.010 & 0.924 \\
\hline TG & -0.317 & 0.003 \\
\hline $\begin{array}{c}\text { P-value: Spearman's correlation test. BMl; body mass index, HOMA-IR; } \\
\text { Homeostasis model assessment insulin resistance, TC; total cholesterol, }\end{array}$ \\
$\begin{array}{c}\text { LDL-C: low-density lipoprotein cholesterol, HDL-C: high-density lipoprotein } \\
\text { cholesterol, TG: triglyceride. }\end{array}$
\end{tabular}

Our study showed that the Spexin levels were significantly lower in all groups than in the control group and lower in the NOD and OND than in the NOND. Spexin is a neuropeptide. The gene that encoded Spexin (Ch12:orf39) was the most downregulated gene in obese omental and sc human fat (24). Spexin not only decreased bodyweight but also improved glucose tolerance by reducing IR along with $\mathrm{HbAlc}^{(25)}$. These results coincide with the results of Karaca et al., and Al-Daghriet al. ${ }^{(26-27)}$ who found that the median fasting serum Spexin levels were significantly lower in diabetic than in the control subjects that recommends that Spexin may affect the metabolism of glucose. Also, Walewski et al. and Behrooz et al. ${ }^{(10,28)}$ found considerably lower concentrations of Spexin in obese than in the lean adults and children respectively and suggested a possible satiety-inducing function for it in humans. On the other hand, our results were opposing to the results of Hodges et al. ${ }^{(8)}$ who evaluated the glucose ingestion effect on the concentration of Spexin in the blood in adolescents. The authors stated that the me dian on centration of the fasting Spexin in the serum was not different between the study groups and it did not show considerable correlation with any of the body fitness, composition, or biochemical measurements in the blood. Our study showed that only 5 cases $(5.8 \%)$ had IR; 4 of them had MS and only 1 with no-MS. However, this difference didn't achieve a statistical significance, probably due to the small sample size. Also, it showed that BMI, WC, HC, WHR, and HOMA-IR were significantly higher in patients with MS than in those with NO-MS. In accordance with the $3^{\text {rd }}$ Report of The National Cholesterol Education Program (NCEP) Expert Panel(29) which defined MS as: 1) abdominal obesity in which WC $>102 \mathrm{~cm}$ (men), and $>88 \mathrm{~cm}$ (women); 2) TG $\geq 150 \mathrm{mg} / \mathrm{dL}$; 3) $\mathrm{HDL}$ $C<40 \mathrm{mg} / \mathrm{dL}$ in men and $<50 \mathrm{mg} / \mathrm{dL}$ in women; 4) blood pressure $\geq 130 / \geq 85 \mathrm{~mm} /$ $\mathrm{Hg}$; and 5) $\mathrm{FBG} \geq 110 \mathrm{mg} / \mathrm{dL}$. Obesity results in IR that together put stress on $\beta$-cells, resulting in a $\beta$-cell failure and a progressive decrease in the secretion of insulin( ${ }^{(30)}$. Because of IR, more amounts of insulin are released at any serum glucose level. 


\begin{tabular}{|c|c|c|c|c|}
\hline Statistic & MS & No-MS & $Z$ value & P-value \\
\hline $\begin{array}{l}\text { BMI }\left(\mathrm{kg} / \mathrm{m}^{2}\right) \\
\quad \text { Median (IQR) } \\
\text { Range } \\
\quad \text { Mean Rank }\end{array}$ & $\begin{array}{c}34.2(29-38.7) \\
26.5-50.2 \\
52.19\end{array}$ & $\begin{array}{c}28.0(23.7-35.6) \\
20.3-45.2 \\
30.84\end{array}$ & -3.894 & $<0.001$ \\
\hline $\begin{array}{l}\text { WC }(\mathrm{cm}) \\
\text { Median (IQR) } \\
\text { Range } \\
\text { Mean Rank } \\
\end{array}$ & $\begin{array}{c}109(100-117) \\
85-134 \\
56.14 \\
\end{array}$ & $\begin{array}{c}86(80-102) \\
53-125 \\
25.09 \\
\end{array}$ & -5.670 & $<0.001$ \\
\hline $\begin{array}{l}\mathrm{HC}(\mathrm{cm}) \\
\text { Median (IQR) } \\
\text { Range } \\
\text { Mean Rank }\end{array}$ & $\begin{array}{c}120(112-130) \\
102-150 \\
54.68 \\
\end{array}$ & $\begin{array}{c}103(96-114) \\
80-144 \\
27.21\end{array}$ & -5.013 & $<0.001$ \\
\hline $\begin{array}{l}\text { WHR } \\
\qquad \text { Median (IQR) } \\
\text { Range } \\
\text { Mean Rank }\end{array}$ & $\begin{array}{c}0.89(0.86-0.93) \\
0.73-1.03 \\
49.46\end{array}$ & $\begin{array}{c}0.86(0.81-0.90) \\
0.38-0.98 \\
34.37\end{array}$ & -2.809 & 0.005 \\
\hline $\begin{array}{l}\text { Fasting insulin } \\
\text { Median (IQR) } \\
\text { Minimum-Maximum }\end{array}$ & $\begin{array}{c}5.6(4.1-8.4) \\
1.4-20 \\
\end{array}$ & $\begin{array}{c}3.7(1.9-5.1) \\
1.2-8 \\
\end{array}$ & -4.428 & $<0.001$ \\
\hline $\begin{array}{l}\text { HOMA-IR } \\
\text { Median (IQR) } \\
\text { Minimum-Maximum }\end{array}$ & $\begin{array}{c}2.48(1.38-3.90) \\
0.29-14.62\end{array}$ & $\begin{array}{c}0.83(0.47-1.27) \\
0.19-3.32\end{array}$ & -5.929 & $<0.001$ \\
\hline
\end{tabular}

The present study showed also that FI was significantly higher in the OD than in the three all other groups. HOMA-IR was significantly higher in OD than in the OND and NOND. It was also higher in OD than in the NOD but this difference was statistically not significant. This study revealed that there was a significantly negative correlation between Spexin and age, FI, HOMA-IR, $\mathrm{BMI}, \mathrm{TC}, \mathrm{LDL}-\mathrm{C}$, and TG. These results were in accordance with the previous studies by Walewski et al., and Kumar et al. ${ }^{(10,31)}$ who reported that expression of Spexin in the adipose tissue and its levels in the blood were majorly reduced in the subjects suffering from obesity. Chen et al.(32) detected that the levels of serum Spexin were decreased in IR obese children in comparison with the non-IR obese children and serum Spexin levels correlated significantly and inversely with FI level and HOMA-IR in obese children. Also, Karaca et al. and AlDaghriet al. 26,27$)$ reported that Spexin inversely correlated with the blood glucose level, HbA1c, TG, and LDL-C. The limitations in our study were small sample size, factors that might affect Spexin such as physical activity and dietary intake were not taken into consideration.

\section{Conclusion}

We concluded that Spexin plays an important role in glucose homeostasis and li 
lipid metabolism. The presence of diabetes is associated with lower Spexin levels. Spexin levels were found to be negatively correlated with age, BMI, FI, TC, LDL-C, TC, and HOMA-IR. To understand the exact function of this peptide and to validate the observations in the current study, further investigations and additional studies on larger populations are required.

\section{Acknowledgment}

We would like to thank all the participating patients, the nurses who helped with anthropometric measurements and vital signs assessments. Thanks to LAB technicians for assisting with blood sample collection, preservation, and results collection.

\section{Financial support: None.}

\section{Conflicts of interest: None}

\section{References}

1. Ogurtsova K, da Rocha Fernandes JD, Huang $\mathrm{Y}$, et al. IDF Diabetes Atlas: Global estimates for the prevalence of diabetes for 2015 and 2040. Diabetes Res Clin Pract. 2017;128: 40-50.

2. Zheng Y, Ley SH, Hu FB. Global etiology and epidemiology of type 2 diabetes mellitus and its complications. Nat Rev Endocrinol. 2018 Feb;14(2):88-98.

3. Chatterjee S, Khunti K, Davies MJ. Type 2 diabetes. Lancet. 2017 Jun 3;389 (10085): 2239-2251.

4. Sinha R, Dufour S, Petersen KF, et al. Assessment of skeletal muscle triglyceride content by (1) $\mathrm{H}$ nuclear magnetic resonance spectroscopy in lean and obese adolescents: relationships to insulin sensitivity, total body fat, and central adiposity. Diabetes. 2002; 51(4):1022-7.

5. Carlsson LM, Peltonen M, Ahlin S, et al. Bariatric surgery, and prevention of type 2 diabetes in Swedish obese subjects. N Engl J Med. 2012 Aug 23;367(8):695-704.

6. Behrooz $M$, Vaghef-Mehrabany $E$, Ostadrahimi A. Different Spexin level in obese vs normal-weight children and its relationship with obesity-related risk factors. Nutr Metab Cardiovasc Dis. 2020 Apr 12;30 (4) :674-682.

7. Wong MK, Sze KH, Chen T, et al. Goldfish Spexin: solution structure and novel function as a satiety factor in feeding control. Am J Physiol Endocrinol Metab. 2013 Aug 1;305(3): E34866.

8. Hodges SK, Teague AM, Dasari PS, et al. Effect of obesity and type 2 diabetes, and glucose ingestion on circulating Spexin concentration in adolescents. Pediatr Diabetes. 2018 Mar;19(2):212-216.

9. Kim DK, Yun S, Son GH, et al. Coevolution of the Spexin /galanin/kisspeptin family: Spexin activates galanin receptor type II and III. Endocrinology. 2014 May;155(5):1864-73.

10. Walewski JL, Ge F, Lobdell $\mathrm{H}$ 4th, et al. Spexin is a novel human peptide that reduces adipocyte uptake of longchain fatty acids and causes weight loss in rodents with diet-induced obesity. Obesity (Silver Spring). 2014 Jul;22(7):1643-52.

11. Karaca A, Bakar-Ates F, Ersoz-Gulcelik N. Decreased Spexin Levels in Patients with Type 1 and Type 2 Diabetes. Med Princ Pract. 2018;27(6):549-554.

12. Sassek M, Kolodziejski PA, Szczepankiewicz D, et al. Spexin in the physiology of pancreatic islets-mutual interactions with insulin. Endocrine. 2019 Mar;63(3):513-519.

13. American Diabetes Association. 2. Classification and Diagnosis of Diabetes: Standards of Medical Care in Diabetes2018. Diabetes Care. 2018 Jan;41(Suppl 1): $\mathrm{S} 13-\mathrm{S} 27$.

14. Allain CC, Poon LS, Chan CS, et al. Enzymatic determination of total serum 
cholesterol. Clin Chem. 1974 Apr;20 (4):470-5.

15. Fossati P, Prencipe L. Serum triglycerides determined colorimetrically with an enzyme that produces hydrogen peroxide. Clin Chem. 1982;28(10):207780.

16. Williams P, Robinson D, Bailey A. Highdensity lipoprotein, and coronary risk factors in normal men. Lancet. 1979 Jan;1(8107):72-5.

17. Trinder P. Determination of blood glucose using 4-amino phenazone as oxygen acceptor. J Clin Pathol. 1969 Mar;22(2):246.

18. Trivelli LA, Ranney HM, Lai HT. Hemoglobin components in patients with diabetes mellitus. N Engl J Med. 1971 Feb 18;284(7):353-7.

19. Matthews DR, Hosker JP, Rudenski AS, et al. Homeostasis model assessment: insulin resistance and beta-cell function from fasting plasma glucose and insulin concentrations in man. Diabetologia. $1985 \mathrm{Jul} ; 28(7): 412-9$.

20. Grundy SM, Barnett JP. Metabolic and health complications of obesity. Dis Mon. 1990 Dec;36(12):641-731.

21. Bays HE, Toth PP, Kris-Etherton PM, et al. Obesity, adiposity, and dyslipidemia: a consensus statement from the National Lipid Association. J Clin Lipidol. 2013 Jul-Aug;7(4):304-83.

22. do Carmo JM, da Silva AA, Wang $Z$, et al. Obesity-Induced Hypertension: Brain Signaling Pathways. Curr Hypertens Rep. 2016 Jul;18(7):58.

23. Blüher M. Obesity: global epidemiology and pathogenesis. Nat Rev Endocrinol. 2019 May;15(5):288-298.

24. Walewski JL, Ge F, Gagner M, et al. Adipocyte accumulation of long-chain fatty acids in obesity is multifactorial, resulting from increased fatty acid uptake and decreased activity of genes involved in fat utilization. Obes Surg. 2010 Jan;20(1):93-107. Oct 29.

25. Ge JF, Walewski JL, Anglade D, et al. Regulation of Hepatocellular Fatty
Acid Uptake in Mouse Models of Fatty Liver Disease with and without Functional Leptin Signaling: Roles of NfKB and SREBP-1C and the Effects of Spexin. Semin Liver Dis. 2016 Sep; 36(4):360-372.

26. Karaca A, Bakar-Ates F, Ersoz-Gulcelik N. Decreased Spexin Levels in Patients with Type 1 and Type 2 Diabetes. Med Princ Pract. 2018;27(6):549-554.

27. Al-Daghri NM, Al-Hazmi HA, Al-Ajlan A, et al. Associations of Spexin and cardiometabolic parameters among women with and without gestational diabetes mellitus. Saudi J Biol Sci. 2018 May;25(4):710-714.

28. Behrooz M, Vaghef-Mehrabany $E$, Ostadrahimi A. Different Spexin level in obese vs normal-weight children and its relationship with obesity-related risk factors. Nutr Metab Cardiovasc Dis. 2020 Apr 12;30(4):674-682.

29. National Cholesterol Education Program (NCEP) Expert Panel on Detection, Evaluation, and Treatment of High Blood Cholesterol in Adults (Adult Treatment Panel III). Third Report of the National Cholesterol Education Program (NCEP) Expert Panel on Detection, Evaluation, and Treatment of High Blood Cholesterol in Adults (Adult Treatment Panel III) final report. Circulation. 2002 Dec 17;106(25):3143-421.

30. DeFronzo RA, Abdul-Ghani MA. Preservation of $\beta$-cell function: the key to diabetes prevention. J Clin Endocrinol Metab. 2011 Aug;96(8):2354-66.

31. Kumar $S$, Hossain $M J$, Inge $T$, et al. Roux-en- $Y$ gastric bypass surgery in youth with severe obesity: 1-year longitudinal changes in Spexin. Surg Obes Relat Dis. 2018 Oct;14(10):1537-1543.

32. Chen T, Wang F, Chu Z, et al. Circulating Spexin Decreased and Negatively Correlated with Systemic Insulin Sensitivity and Pancreatic $\beta$ Cell Function in Obese Children. Ann Nutr Metab. 2019;74(2):125-131. 